\title{
Trade-off between water pollution prevention, agriculture profit, and farmer practice — an optimization methodology for discussion on land-use adjustment in China
}

\author{
Liu Jianchang $\cdot$ Zhang Luoping $\cdot$ Zhang Yuzhen • Deng Hongbing
}

Received: 3 June 2014 / Accepted: 28 October 2014 / Published online: 13 November 2014

(C) Springer International Publishing Switzerland 2014

\begin{abstract}
Agricultural decision-making to control nonpoint source (NPS) water pollution may not be efficiently implemented, if there is no appropriate cost-benefit analysis on agricultural management practices. This paper presents an interval-fuzzy linear programming (IFLP) model to deal with the trade-off between agricultural revenue, NPS pollution control, and alternative practices through land adjustment for Wuchuan catchment, a typical agricultural area in Jiulong River watershed, Fujian Province of China. From the results, the lower combination of practice 1 , practice 2 , practice 3 , and practice 7 with the land area of 12.6, 5.2, 145.2, and $85.3 \mathrm{hm}^{2}$, respectively, could reduce NPS pollution load by $10 \%$. The combination yields an income of 98,580 Chinese
\end{abstract}

\section{Jianchang $(\bowtie)$}

Transport Planning and Research Institute, Ministry of Transport, Building A2 of Shuguangxili,Chaoyang District, Beijing 100028, China

e-mail: amoytiger@163.com

\section{Z. Luoping}

State Key Laboratory of Marine Environmental Science, Environmental Science Research Center of Xiamen University, Xiamen 361005, China

\section{Z. Yuzhen}

Fujian Research Academy of Environmental Sciences, Environmental Protection Bureau of Fujian Province, Fuzhou 361005, China

D. Hongbing

State Key Laboratory of Urban and Regional Ecology, Research Center for Eco-Environmental Sciences, Chinese Academy of Sciences, Beijing 100085, China
Yuan/a. If the pollution reduction is $15 \%$, the higher combination need practice 1, practice 2, practice 3, practice 5, and practice 7 with the land area of 54.4, 23.6, $18.0,6.3$, and $85.3 \mathrm{hm}^{2}$, respectively. The income of this combination is 915,170 Chinese Yuan/a. The sensitivity analysis of IFLP indicates that the cost-effective practices are ranked as follows: practice $7>$ practice $2>$ practice $1>$ practice $5>$ practice $3>$ practice $6>$ practice 4 . In addition, the uncertainties in the agriculture NPS pollution control system could be effectively quantified by the IFLP model. Furthermore, to accomplish a reasonable and applicable project of land-use adjustment, decisionmakers could also integrate above solutions with their own experience and other information.

Keywords Nonpoint source pollution · Optimization model · Best management practices (BMPs) · Scenarios simulation - Watershed integrated management

\section{Introduction}

Nonpoint source (NPS) pollution is an important water quality management problem. NPS pollution occurs when rainfall, snowmelt, or irrigation water run over land or through the ground, pick up pollutants, and deposit them into rivers, lakes, and coastal waters or introduce them into ground water (Arnold et al. 1993). It can be said that water movement is like an engine, and agricultural land use is the fuel (Hassen et al. 2004). The increases in nutrient losses and riverine nutrient loads have caused the eutrophication of many coastal and 
freshwater ecosystems (Nixon et al. 1995; Vitousek et al. 1997; Carpenter et al. 1998; Cao and Zhu 2000). A watershed protection approach is an important strategy to effectively protect a watershed and thereby restore aquatic ecosystems and protect human health (Bhuyan et al. 2003).

Like other conventional methods, a number of best management practices (BMPs) have to be planned and their effectiveness has to be tested (Stewart et al. 1975; US-NRC 1993; Sugiharto et al. 1994; Correll 1996). Since this approach of NPS pollution prevention is based on studies on the watersheds in several developed countries, it mainly emphasizes the effectiveness of pollution control. Nonetheless, with increasing pressure from dense populations, there are different opinions between environmental protection and socioeconomic development in numerous watersheds in China. Agricultural NPS pollution is always related to the desire of farmers for profits over agricultural lands.

For example, on one hand, on-farm practices applied to reduce surface runoff or phosphorus export by increasing infiltration may increase nitrogen leaching (Pionke et al. 2000). On the other hand, some practices with high efficiency on control NPS pollutants may not be adopted for their high cost in farming; however, those with low efficiency could often be applied willingly by Chinese farmers owing to their low cost or good agricultural profit.

The traditional framer practices only focused on NPS pollution prevention may not be efficiently implemented, if there is no appropriate consideration for the tradeoff between cost and benefit. This method, however, may result in enormous economic costs especially when the large sums of land need to be occupied by lots of BMPs. Therefore, it is important to attain cost-effective management combination by which the NPS pollution can be better controlled, while the cost can be kept to a minimum. In the same way, the design and assessment of multifunctional agricultural landscapes could be supported by the exploration of trade-offs between financial returns from agriculture, land-use quality, and environmental quality (Jeroen et al. 2007). For this reason, an integrated approach that takes into account both economy and environment, both land-use and practice adjustment are needed.

Since the blind combination of farmer practices in a watershed may result in enormous cost especially when a great amount of land needs to be occupied by lots of practices, optimization model can be employed to couple with BMPs combination. However, the optimizing efforts can also be inefficient due to various uncertainties existing in stochastic, interval, and fuzzy formats in agricultural systems. Thus, it is desired to develop improved methods to effectively quantify the balance between the efficiency of NPS pollution control and the reduction of practice application cost by considering those uncertainties (Liu et al. 2005a, b). In this respect, this paper presented an interval-fuzzy linear programming (IFLP) as a system optimization model to cope with such problems.

Over the past decades, a number of optimization methods were developed for environmental management under uncertainty. The majority of these methods are related to fuzzy mathematical programming (FMP) (Lee et al. 1991; Chang and Lu 1997; Chanas and Zielinski 2000; Cui et al. 2011; James et al. 2013; Su et al. 2011; Wang et al. 2011, 2013; Wang and Huang 2013a, b), stochastic mathematical programming (SMP) (Li 2003), and interval mathematical programming (IMP) (Huang et al. 1993, 1994a, 1995b; Chang and Lu 1997; Yeomans and Huang 2003; Yeomans et al. 2003; Liu et al. 2006; Hu et al. 2014; Li et al. 2014). Although the IMP proves to be an effective approach in dealing with uncertainties, it encounters difficulties when the model's right-hand-side coefficients are highly uncertain. Several integrated IMP, FMP, and/or SMP methods were developed to tackle such a difficulty (Huang et al. 1993, 1994b, 1995a; Zou et al. 2000; Luo et al. 2003; Maqsood and Huang 2003). Among them, interval-fuzzy linear programming (IFLP) (Huang et al. 1993; Wang and Huang 2013a, b; Hu et al. 2014; Li et al. 2014), which is a hybrid of interval linear programming (ILP) and flexible fuzzy linear programming (FLP), is useful in accounting for uncertainties expressed as discrete intervals and/or fuzzy membership functions.

\section{Materials and methods}

\section{Site description}

The study area chosen was Wuchuan catchment located in the upstream Jiulong Western River, Fujian Province, southeast China (Fig. 1). Rainfall is strongly influenced by the monsoon system. The annual average rainfall was $1720 \mathrm{~mm}$. Rainfall recorded between July and September (wet season) in average was $1078 \mathrm{~mm}$, 
Fig. 1 Map of China showing the location of the Wuchuan catchment

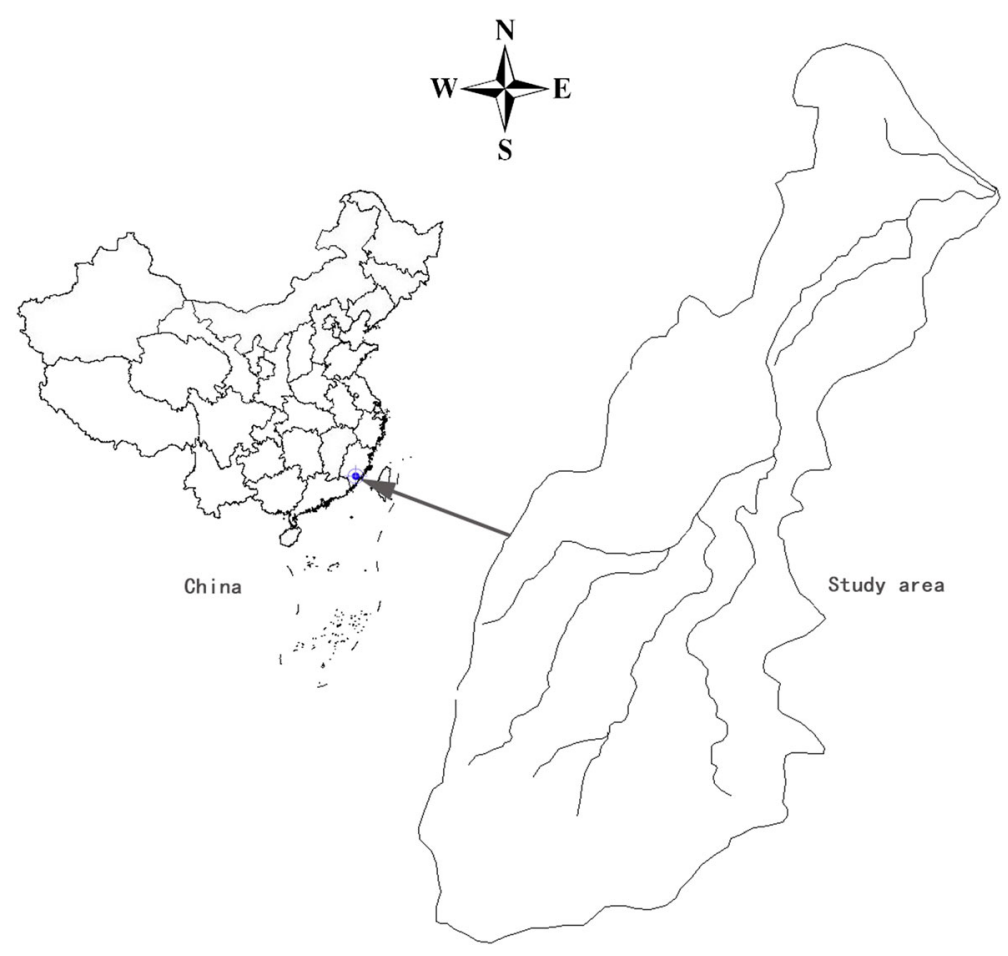

accounting for about $66 \%$ of the total rainfall. The landform is characterized by rolling and undulating hills. The catchment elevation varies between 5.0 and $130 \mathrm{~m}$. The heavily weathered granite base has been dissected by small streams. Agriculture and horticulture are usually developed in the flat alluvial valley. Red earth and lateritic red earth are the main soil types in the whole catchment, with $\mathrm{pH}$ values ranging from 4.0 to 4.8 (mean value 4.5). As a result of increasing the control of soil erosion, the rate of soil erosion in this catchment has recently decreased to $475 \mathrm{t} / \mathrm{km}^{2} /$ year (Zhang 2003). In 2002, the land use in catchment consisted of forestry, pastures, bamboo, orchards, banana, vegetables, sugarcane fields, paddy fields, fishery ponds, and residences, with area percentages of 29.9, $5.7,6.9,22.3,19.2,1.6,5.6,1.8,2.5$, and $4.5 \%$, respectively, as shown in Fig. 2.

By the end of the year 2002, a population of 8366 with an average income of over 2500 Chinese Yuan per capita has resided in the five villages, one special cultivation farm, and two horticultural companies within catchment. The catchments are completely agricultural, with no industrial pollution impacts. The dominant economic activity in the area is agronomic farming with a little scattered livestock breeding and multi-pond fishery. The vegetation, soil, and climate conditions are typical of the Jiulong River watershed. The subtropical weather, beneficial for crop growth, motivates farmers to increase the number of crop rotations in a year as much as possible. The steep terrain and erosive soil cause farmers to increasingly overuse nutrient fertilizer regardless of the precise nutrient balance in fields required to raise agricultural yields, with the result that nutrients will flow into the streams when irrigation is greatly increased or a storm occurs after the application of fertilizer. The amount of chemical fertilizer and manure applied to the agricultural fields in this area far exceeds the demand of crops, and the rate of $\mathrm{N}$ losses resulting from $\mathrm{N}$ overuse is the highest in the Jiulong River watershed (Cao and Zhu 2000). The reasons for choosing the location of the study site can be summarized as follows: (1) its agriculture is very typical of the Chinese subtropics, (2) its land tillage and land uses are very complex, (3) There is almost no industrial emission into stream, and (4) the severe pollution of coastal waters by the agricultural NPS is of increasing public concern.

The excessive use of commercial inorganic fertilizers for raising crop yield and meeting the demand of population growth in this area has resulted in increased nutrient losses into the adjacent surface water. The increases in nutrient losses and riverine nutrient loads 
Fig. 2 Land use in Wuchuan catchment

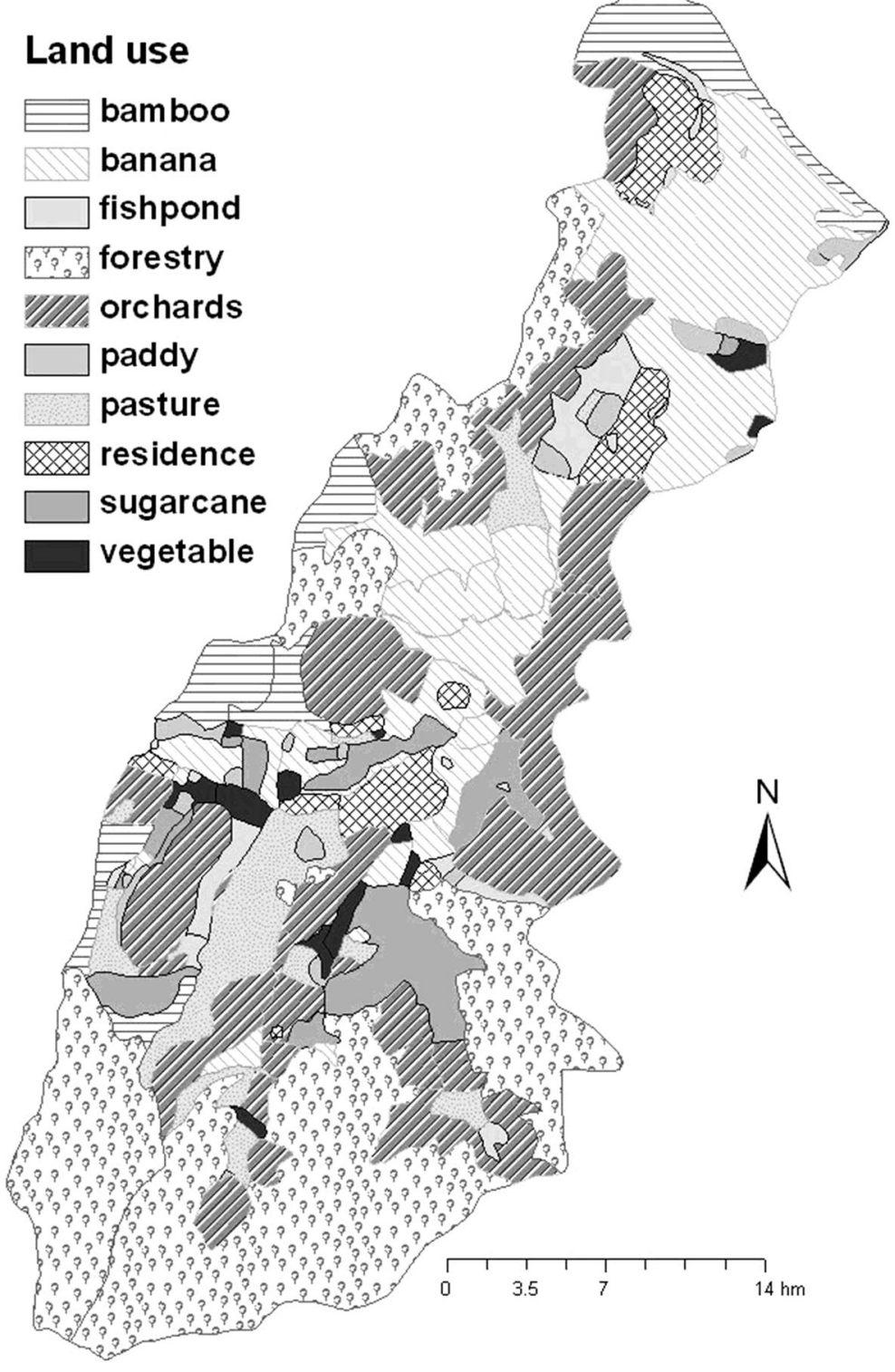

have caused the eutrophication of many coastal and freshwater ecosystems. There is not any point source pollution in the catchment. River runoff and peak flow rate at the outlet of catchment were measured using manual recorder. After field sample, total nitrogen (TN), dissolved nitrogen (DN), total phosphorus (TP), dissolved phosphorus (DP), and suspended solid (sediment, SS) in the catchment river were measured in the laboratory through colorimetric analyses and weight loss method. The annual concentrations of nutrient pollution are listed in Table 1.
The relative weight in terms of the pollutant loads of animals and human beings is determined according to the ingredients of nutrient element equivalent which is shown in Table 2 (Zhang 2003; Zhang et al. 2009).

Proposal of farm practices

Two essential steps are required during the designing process for BMPs to control agricultural nonpoint source pollution in this study. The first step is the sensitivity analysis of Agricultural Nonpoint Source (AGNPS) - a simulation management model. It is a precondition to put 
Table 1 Average annual concentrations of nutrient pollution monitored at outlet of catchment

\begin{tabular}{llllllll}
\hline $\begin{array}{l}\text { Observed } \\
\text { concentration }\end{array}$ & Runoff $\left(\mathrm{m}^{3}\right)$ & $\begin{array}{l}\text { Peak flow } \\
\left(\mathrm{m}^{3} / \mathrm{s}\right)\end{array}$ & $\begin{array}{l}\text { Sediment } \\
(\mathrm{mg} / \mathrm{L})\end{array}$ & $\begin{array}{l}\text { Total } \\
\text { nitrogen }(\mathrm{mg} / \mathrm{L})\end{array}$ & $\begin{array}{l}\text { Dissolved } \\
\text { nitrogen }(\mathrm{mg} / \mathrm{L})\end{array}$ & $\begin{array}{l}\text { Total } \\
\text { phosphorus }(\mathrm{mg} / \mathrm{L})\end{array}$ & $\begin{array}{l}\text { Dissolved } \\
\text { phosphorus }(\mathrm{mg} / \mathrm{L})\end{array}$ \\
\hline Flood season & $69,141.61$ & 0.83 & 66.91 & 10.06 & 7.06 & 0.40 & 0.15 \\
Dry season & $18,194.25$ & 0.32 & 249.06 & 3.75 & 3.31 & 0.43 & 0.13 \\
Annual average & $48,762.66$ & 0.63 & 94.23 & 9.97 & 7.08 & 0.41 & 0.14 \\
\hline
\end{tabular}

forth special control practices which aim at the high benefit of nonpoint source pollution reduction. The percentage of the pollutant abatement of practices is determined during this period. The second step requires the system analysis of practices proposed in the first step. In a specific watershed, each practice has its own pollutant reduction potential and economic cost. In order to evaluate the cost-effectiveness of alternative practices, operation research has to be carried out. Through these two steps, cost-effective feasibility, with the best control coefficient of practices, is highlighted based on economic and environmental analysis. An optimization model with interval numbers and input uncertainty was applied in this case study. Seven management practice scenarios were set up to control nonpoint source pollution in the catchment after the sensitivity analysis of AGNPS 5.0 model. Meanwhile, alternative methods have different costs and practicability. Particularly, higher cost would be paid for implementing these practices if fewer practices are adopted blindly. Inexact system design model can help select and assemble alternative practices. To accomplish a reasonable and applicable project, decision-makers can integrate the solutions of the model with their own experience and other relevant information. The generated program can guarantee a maximized economic output of the watershed with the minimum nonpoint source pollution contribution.

Among the initial catchment data required for the model, the moisture condition and the storm type for

Table 2 Average content of contaminants in livestock manure ( $\mathrm{kg} / \mathrm{t})$

\begin{tabular}{llll}
\hline Item & $\mathrm{NH}_{3}-\mathrm{N}$ & $\mathrm{TP}$ & $\mathrm{TN}$ \\
\hline Droppings of cattle & 1.71 & 1.18 & 4.37 \\
Urine of cattle & 3.47 & 0.4 & 8 \\
Droppings of swine/human & 3.08 & 3.41 & 5.88 \\
Urine of swine/human & 1.43 & 0.52 & 3.3 \\
Droppings of sheep and goat & 0.8 & 2.6 & 7.5 \\
Droppings of poultry & 2.8 & 5.8 & 10.4 \\
\hline
\end{tabular}

the event have to be selected. The runoff curve numbers depend on the soil-water content (moisture condition), and it is one of the parameters that affect the runoff and peak flow rates more substantially. Based on the study of a previous project in this catchment (Zhang 2003; Liu et al. 2008), seven management practice scenarios have been proposed according to the land use of catchment as described below:

Practice 1: Ploughing the pasture field along contour lines instead of following the direction of the slope. This practice occupied all pasture area, with $5.7 \%$ of all the catchment. The distance of two neighbor contour lines could be designed in accordance with the realistic terrain. This practice was designed to change topography condition in order to reduce hydrology and nutrients loss.

Practice 2: Increasing the building of multi-fishpond systems in other suitable areas. Fishpond system was a conventionally distinguished landscape which was gradually formed by local farmers based on the special natural geography feature of the catchment over a long period. This practice was an antecedent method to control NPS pollutants. Here, the practice will be further applied in accordance with its corresponding area. The unit of incremental fishpond area was $2.5 \%$ of all large catchment.

Practice 3: Reducing $30 \%$ of total latest fertilizer application quantity including organic and inorganic fertilizer in crop field. From the description of the study site, chemical and organic fertilizers were overused widely in the catchment for the reason of more crop rotations and more erosive oil texture. The excessive fertilizer loss to environment in the area was highlighted as a serious problem by public 
concerns on Jiulong River water quality. The fertilizer amount and application methods used in the fields of all land use were tailed up during crop development periods except for fishery, residence, forestry, and pasture (Zhang 2003).

Practice 4: Planting trees on the present slope pasture. Surface condition constant was also a weight parameter to control NPS pollution according to the sensitive analysis of the AGNPS model (Zhang 2003; Liu et al. 2008). The change of the parameter would accordingly occur if the current pasture field was adjusted to the forest. The area concerned with the practice was $5.7 \%$ that of the large catchment.

Practice 5: Planting green manure or constructing filtration strips in the crop fields near the estuary that is burdened with more soluble nitrogen pollutant than that of other fields. The fertilizer application amount in these fields was limited under the average level of all the catchment. If the alternative of filtration strip was implemented, the breadth of the strip can be over $10 \mathrm{~m}$ at both sides of the stream. The practice would occupy $3 \%$ of all the catchment area.

Practice 6: Reducing $30 \%$ of pollution loading from all residence. Livestock manure and domestic sewage were one of the main sources of environmental pollution at present, and serious pollution was shown on pollution distribution graph based on geographic information system (Zhang 2003). The total nitrogen from potentially applied manure and domestic sewage was $70.5 \mathrm{t} \mathrm{a}$ year, and the total phosphorus was $16.7 \mathrm{t}$. A reduction of $30 \%$ shows a respective decrease of $21.2 \mathrm{t}$ of total nitrogen and $50.0 \mathrm{t}$ of total phosphorus.

Practice 7: Applying 30\% crop residues to land after crops were harvested. The non-tillage or application of crop residues would reduce soil erosion. The baseline area of sugarcane, paddy, and vegetable in land-use map, about $9.0 \%$ of all the objective catchment area, was considered during BMP simulation.
All these practices are implemented in the corresponding places showed in Table 3 according to the land use pattern of the catchment, and the final programmed area proportion for which these practices would be occupied will be determined during the optimization procedure later. The practices above were simulated after the calculation and validation of an agricultural nonpoint source pollution model (AGNPS) on the catchment in a previous project study (Zhang 2003; Chen et al. 2006; Liu et al. 2008). Table 4 shows the results of the simulated environmental control of each management practice (Liu et al. 2008).

\section{IFLP model formulation}

Many factors act as barriers in quantifying nonpoint source load with certainty sufficient for the land-use adjustment of agricultural activities which discharge pollutants (e.g., N and P) into the downstream waterbody. For nonpoint sources, the loads changed by BMPs are not measured with certainty but in fact represent a probability distribution around the actual discharge load (Li et al. 2014). This is due to the facts that (1) nonpoint source loads are influenced by stochastic events such as temperature and precipitation, (2) nonpoint loads cannot be measured at the source level, and (3) there is imperfect knowledge about the relationship between loadings and control practice changes (Bartfeld 1993; Malik et al. 1993). In response to such uncertainties above, it needs to optimize the area of cropland and BMPs by maximizing total agricultural net benefit (Li et al. 2014).

In an interval-fuzzy linear programming (IFLP) model, the uncertain parameters were expressed as number intervals without any distributional information that is always required in fuzzy and stochastic programming. The IFLP allows the interval information to be directly communicated into the optimization process and resulting solution (Huang et al. 1995b; Wang and Huang 2013a, b; Hu et al. 2014). The abstract function of system design model based on an interval number optimization can be written as follows (Huang et al. 1993; Liu et al. 2006):

$$
\begin{aligned}
& \max f^{ \pm}=C^{ \pm} x^{ \pm} \\
& \text {st. } A^{ \pm} x^{ \pm}<B^{ \pm} \\
& x^{ \pm} \geq 0
\end{aligned}
$$

where $A^{ \pm} \in\left\{R^{ \pm}\right\}_{m \times n}$ represents the matrix of technique coefficients which are the rates of pollution emission for 
Table 3 Land use on which seven practices will be implemented

\begin{tabular}{llllllll}
\hline Item & Practice 1 & Practice 2 & Practice 3 & Practice 4 & Practice 5 & Practice 6 & Practice 7 \\
\hline Land use & Pasture & Fishpond & $\begin{array}{c}\text { Bamboo, mango, } \\
\text { banana, vegetable, } \\
\text { sugarcane, and paddy }\end{array}$ & Pasture & $\begin{array}{c}\text { Pasture, bamboo, } \\
\text { vegetable, sugarcane, } \\
\text { and paddy }\end{array}$ & $\begin{array}{c}\text { Residence } \\
\text { Sugarcane, paddy, } \\
\text { and vegetable }\end{array}$ \\
$\begin{array}{l}\text { Area }\left(\mathrm{hm}^{2}\right) \\
\begin{array}{c}\text { Proportion of } \\
\text { land use (\%) }\end{array}\end{array}$ & 5.7 & 23.6 & 549.3 & 54.4 & 28.7 & 43.2 & 85.3 \\
\end{tabular}

different practices; $B^{ \pm} \in\left\{R^{ \pm}\right\}_{m \times l}$ is the environmental capacity; $C^{ \pm} \in\left\{R^{ \pm}\right\}_{l \times n}$ represents the profit coefficients for each alternative practice; $x^{ \pm} \in\left\{R^{ \pm}\right\}_{n \times l}$ is the controllable decision variable of each alternative method; $f^{ \pm}$is the objective function; and $f^{ \pm}, C^{ \pm}, x^{ \pm}, A^{ \pm}$, and $B^{ \pm}$are the interval numbers.

According to Huang et al. (1993), an interactive solution algorithm has been developed to solve the above problem through analyzing the detailed interrelationships between parameters and variables and between the objective function and constraints. The solution for Eqs. (1)-(3) above can be obtained through a two-step method, where a submodel corresponding to $f^{+}$(when the objective function is to be maximized) is first formulated and solved, and then the relevant submodel corresponding to $f$ can be formulated based on the solution of the first submodel. The formulation of the first submodel is detailed as follows.

The first $K_{1}$ values of the interval numbers in the objective function are assumed nonnegative, and the rest $N-K_{1}$ values of the interval numbers are negative. $C_{j}^{ \pm} \geq$ $0\left(j=1,2, \ldots, K_{1}\right)$ and $C_{j}^{ \pm}<0\left(j=K_{1}+1, K_{1}+2, \ldots, N\right)$.
Then, the procedure of solving the upper maximum objective value is denoted as

$$
\begin{aligned}
& \max f^{+}=\sum_{j=1}^{K_{1}} c_{j}^{+} x_{j}^{+}+\sum_{j=K_{1}+1}^{N} c_{j}^{+} x_{j}^{-} \\
& \mathrm{st} \sum_{j=1}^{K_{1}}\left|a_{i j}\right|^{-} \operatorname{Sign}\left(a_{i j}^{-}\right) x_{j}^{+} / b_{i}^{+} \\
& +\sum_{j=K_{1}+1}^{N}\left|a_{i j}\right|+\operatorname{Sign}\left(a_{i j}^{+}\right) x_{j}^{-} / b_{i}^{-} \leq 1
\end{aligned}
$$

where Sign represents the signal function. It equals to 1 when its independent variables are positive, equals to -1 when its independent variables are negative, and equals to 0 when its independent variables are 0 . The values of $x_{j}^{+}\left(j=1,2, \ldots, K_{1}\right), x_{j}^{-}\left(j=K_{1}+1, K_{1}+2, \ldots, N\right)$, and their corresponding objective maximum value, $f^{+}$, are obtained through solving Eqs. 4 and 5. Furthermore, the values of $x_{j}^{-}\left(j=1,2, \ldots, K_{1}\right), x_{j}^{+}\left(j=K_{1}+1, K_{1}+2, \ldots, N\right)$, and their correlated objective minimum values $f^{-}$are also

\begin{tabular}{|c|c|c|c|c|c|c|c|c|}
\hline \multirow[t]{2}{*}{ Item } & \multirow[t]{2}{*}{ Basic value } & \multicolumn{7}{|c|}{ Reduction percent $(\%)$} \\
\hline & & Practice 1 & Practice 2 & Practice 3 & Practice 4 & Practice 5 & Practice 6 & Practice 7 \\
\hline Runoff $\left(\mathrm{m}^{3}\right)$ & 114,430 & - & 15.06 & - & 9.26 & 5.56 & - & - \\
\hline Peak Flow $\left(\mathrm{m}^{3} / \mathrm{s}\right)$ & 1.72 & - & - & - & 8.14 & 5.23 & - & - \\
\hline SS (ton) & 35.9 & 4.26 & - & - & - & 17.66 & - & 9.01 \\
\hline $\mathrm{PN}(\mathrm{kg})$ & 251.00 & 3.98 & 14.34 & - & - & 21.91 & - & 6.08 \\
\hline DN (kg) & 1843 & - & 14.98 & 25.45 & 10.64 & 33.75 & 4.95 & - \\
\hline PP (kg) & 32.70 & - & 14.98 & - & - & - & - & 6.73 \\
\hline DP (kg) & 10.90 & - & 14.95 & 100.00 & - & - & 7.12 & - \\
\hline
\end{tabular}
worked out in the same method.

Table 4 Environmental performances of seven practices

“_” means no change 
Table 5 Model parameters (1)

\begin{tabular}{|c|c|c|c|c|c|c|c|}
\hline \multirow{2}{*}{ Table 5 Model parameters (1) } & \multirow[t]{2}{*}{ Practice } & \multicolumn{2}{|c|}{ Costs $\left(10^{4}\right.$ Chinese Yuan/a) } & \multicolumn{2}{|c|}{ Reduction of SS (\%) } & \multicolumn{2}{|c|}{ Reduction of PN (\%) } \\
\hline & & Lower $(-)$ & Upper $(+)$ & Upper $(+)$ & Lower $(-)$ & Upper $(+)$ & Lower $(-)$ \\
\hline & 1 & 3.198 & 3.838 & 4.26 & 3.62 & 3.98 & 3.38 \\
\hline & 2 & 11.651 & 17.925 & - & - & 14.34 & 12.19 \\
\hline & 3 & 17.529 & 104.967 & - & - & - & - \\
\hline & 4 & 13.384 & 40.152 & - & - & 10.64 & 9.04 \\
\hline & 5 & 89.535 & 268.875 & 17.66 & 15.01 & 21.91 & 18.62 \\
\hline & 6 & 12.906 & 32.265 & - & - & - & - \\
\hline $\begin{array}{l}\text { Reduction rate is zero when noted } \\
\text { with "_"" }\end{array}$ & 7 & 1.936 & 7.744 & 9.01 & 8.11 & 6.08 & 6.47 \\
\hline
\end{tabular}

According to the functions above, we applied the actual conditions of the Wuchuan catchment to develop a specific inexact optimization model for management practices. The objective is to minimize the total cost and to maximize the profit of implementing all the practices in the area, with the hope to find the expected pollution reduction rates for each pollutant:

$\min f^{ \pm}=\sum_{i=1}^{7}\left(\mathrm{PRACT}_{i}\right)^{ \pm}\left(\mathrm{ECOCO}_{i}\right)^{ \pm}$

$\mathrm{st} \sum_{i=1}^{7}\left(\mathrm{PRACT}_{i}\right)^{ \pm}\left(\mathrm{REDUCT}_{i j}\right)^{ \pm} \geq\left(\mathrm{PERM}_{j}\right)^{ \pm}$

$0 \leq\left(\mathrm{PRACT}_{i}\right)^{ \pm} \leq 1$

$\mathrm{i}=1,2, \ldots, 7 ; \mathrm{j}=1,2, \ldots, 5$

where $\mathrm{PRACT}_{i}$ represents the seven practices; $\mathrm{ECOCO}_{i}$ is the application costs of the seven practices; REDUCT $_{i j}$ represents the expected reduction rates of SS, DN, PN, DP, and PP using the seven practices; and $\mathrm{PERM}_{j}$ is the permitted reduction rates of SS, DN, $\mathrm{PN}, \mathrm{DP}$, and PP associated with the seven practices.

The programming process above was conducted to an iterative procedure in which the desired result was approached. The procedure can help decision-makers develop integrated plans to control NPS pollution and to optimize land-use pattern.

\section{Model preferences}

The cost of each practice was obtained from farmer tracking recorders and field survey. The coefficients of environmental control effectiveness were calculated through the simulation of the AGNPS model (Zhang 2003; Chen et al. 2006; Liu et al. 2008). The catchment river runoff and peak flow rate were measured throughout the year using a manual recorder. Catchment sediment loss was monitored from measuring the suspended sediment in the river. After field sampling, total nitrogen (TN), dissolved nitrogen (DN), sediment nitrogen (SN), total phosphorus (TP), dissolved phosphorus (DP), and sediment phosphorus (SP) were measured in the laboratory by colorimetric analyses, and the suspended solid

Table 6 Model parameters (2)

Reduction rate is zero when noted with "-,"

\begin{tabular}{|c|c|c|c|c|c|c|}
\hline \multirow[t]{2}{*}{ Item } & \multicolumn{2}{|c|}{ Reduction of DN (\%) } & \multicolumn{2}{|c|}{ Reduction of PP (\%) } & \multicolumn{2}{|c|}{ Reduction of DP (\%) } \\
\hline & Upper $(+)$ & Lower $(-)$ & Upper (+) & Lower $(-)$ & Upper (+) & Lower (-) \\
\hline Practice 1 & - & - & - & - & - & - \\
\hline Practice 2 & 14.98 & 12.73 & 14.98 & 12.73 & 14.95 & 12.71 \\
\hline Practice 3 & 25.45 & 22.01 & - & - & 100.00 & 70.00 \\
\hline Practice 4 & - & - & - & - & - & - \\
\hline Practice 5 & 33.75 & 28.69 & - & - & - & - \\
\hline Practice 6 & 4.95 & 4.46 & - & - & 7.12 & 6.41 \\
\hline Practice 7 & - & - & 6.73 & 6.06 & - & - \\
\hline
\end{tabular}


Table 7 Optimal results of simulated pollution reduction

\begin{tabular}{|c|c|c|c|c|c|c|c|}
\hline Item & $\operatorname{Runoff}\left(\mathrm{m}^{3}\right)$ & Peak flow $\left(\mathrm{m}^{3} / \mathrm{s}\right)$ & SS (ton) & $\mathrm{PN}(\mathrm{kg})$ & $\mathrm{DN}(\mathrm{kg})$ & $\mathrm{PP}(\mathrm{kg})$ & $\mathrm{DP}(\mathrm{kg})$ \\
\hline Base value & 114,430 & 1.72 & 35.9 & 251 & 1843 & 32.7 & 10.9 \\
\hline Pollution reduction of the lower combination of practices & $11,443.0$ & 0.2 & 3.6 & 25.1 & 184.3 & 3.3 & 1.1 \\
\hline Pollution reduction of the upper combination of practices & $17,164.5$ & 0.3 & 5.4 & 37.7 & 276.5 & 4.9 & 1.6 \\
\hline
\end{tabular}

(sediment, SS) was measured by weight loss method after ignition at $105^{\circ} \mathrm{C}$. According to the acreage each practice applied to, the parameters used in the system design models with uncertainty were acquired in the former project in the catchment (Zhang 2003; Liu et al. 2008). The calibration and validation of AGNPS 5.0 model (a simulation model of NPS concentration) were done manually in order to select values for the parameters so that the simulation model closely simulates runoff, peak runoff rate, sediment yield and nutrients for each practice, and the combination of all BMPs. Results are shown in Tables 5 and 6.

\section{Results and discussions}

\section{Optimization results}

The Eqs. (6)-(9) are solved using the computer programs coded with Lingo (LINDO Systems Inc. 2006). The combination of all the management practices is applied in the respective fields, and the expected reduction rates are 10 and $15 \%$. The rate was hypothetical according to a pollution prevention objective of the local catchment (Zhang 2003; Liu et al. 2008). With the lower value of the interval numbers, the combination of practices consists of practice 1 , practice 2 , practice 3 , and practice 7, with the land area of 12.6, 5.2, 145.2, and $85.3 \mathrm{hm}^{2}$, respectively. The income of this combination is 98,580 Chinese Yuan/a, and it can achieve a NPS pollution load reduction of $10 \%$. For the upper value of the interval numbers, the combination of practices includes practice 1 , practice 2 , practice 3 , practice 5 , and practice 7 with the land area of 54.4, 23.6, 18.0, 6.3, and $85.3 \mathrm{hm}^{2}$, respectively. It yields the income of 915,170 Chinese Yuan/a with a pollutant load reduction of $15 \%$.

According to the sensitivity analysis of the IFLP model, the order of the cost-effective scores of the seven practices is practice $7>$ practice $2>$ practice $1>$ practice $5>$ practice $3>$ practice $6>$ practice 4 . The ranking is recommended when we assemble these practices in their respective fields. In summary, the best management practice of controlling NPS pollution in this area is practice 7, the application of crop residues in the land near the estuary. The second best is practice 2, building multi-fishpond systems in suitable areas. Although practice 3 and practice 6 have demonstrated excellent environmental benefit, they tend to require higher costs. For this reason, neither practice 3 nor practice 6 is recommended. The optimal results for pollutant reduction and land-use change are elaborated in Tables 7 and 8.

When the results obtained from these higher and lower values of the interval numbers are considered, the decision of land-use adjustment to combine all the practices can be made. It is expected that the decision will be well accepted because it has balanced environmental benefit and economic cost.

\section{Discussion}

From the optimization results, the lower combination can achieve a NPS pollution load reduction of $10 \%$. The income under this condition is 98,580 Chinese Yuan/a, almost equal to the total revenue of 40 farmers. If the pollution reduction is $15 \%$, its benefit is 915,170 Chinese Yuan/a and is approximately equal to the total revenue of 400 farmers. The higher income with less pollution reduction shows a strong marginality of NPS pollution control. That the lower benefit of nearly 40 times and the higher income of nearly 400 times the average income per farmer has in the catchment is acceptable in comparison with 10-15\% NPS pollution reduction, compared to the total population here of 8366.

Both the upper and the lower combination of farmer practices were all including practice 1 , practice 2 , practice 3 , and practice 7 . It indicates that the land-use pattern for which these practices will be applied is in a close relation between pollution prevention and cost minimization. The land use of both practice combinations is involving bamboo, mango, banana, pasture, sugarcane, paddy, and vegetable. The promotion of 


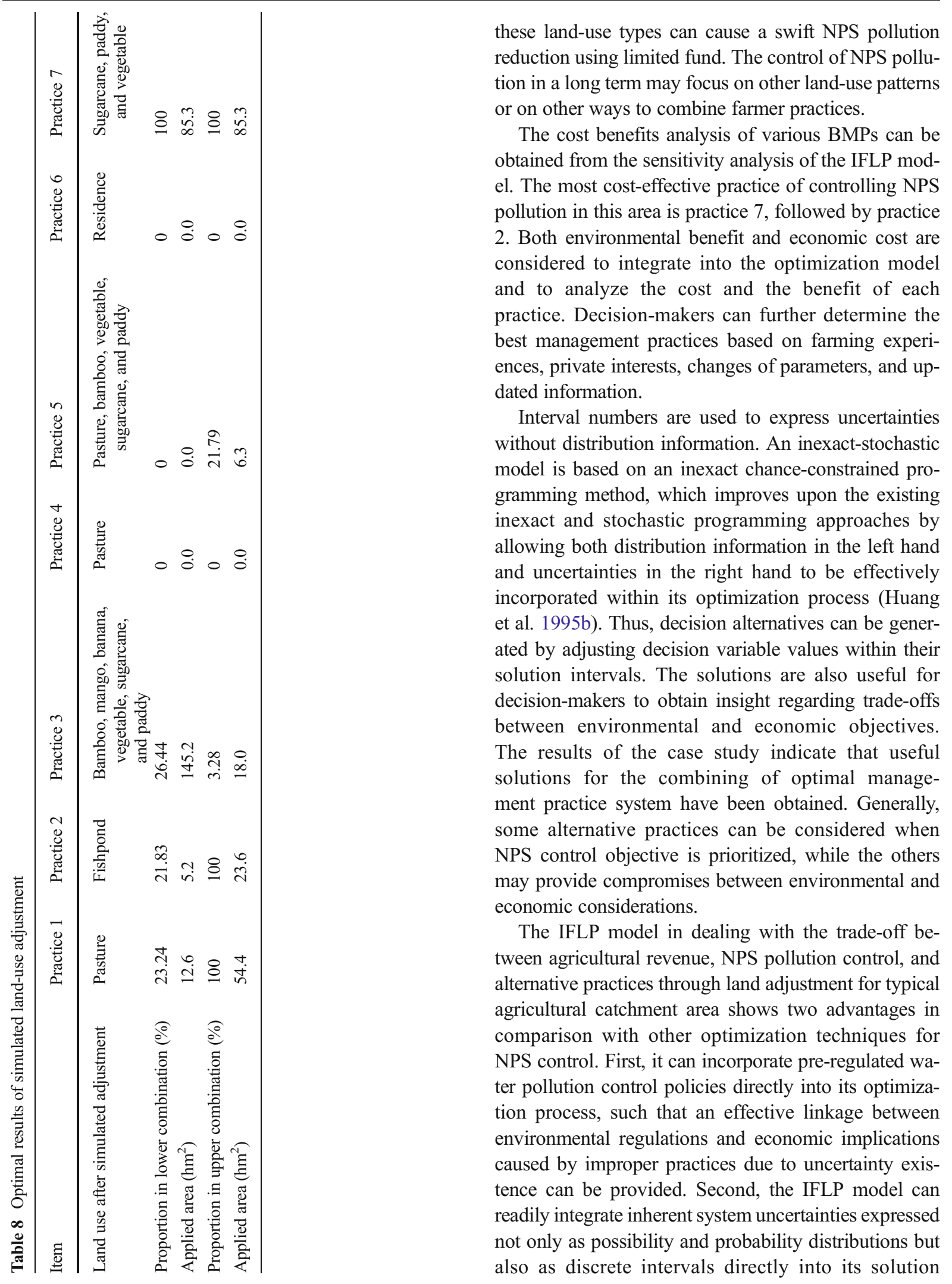


procedure. It can thus help quantify a relationship between the overall satisfaction degree and the system objective under uncertainty, which provide bases for the in-depth analysis of trade-off between pollutant abatement and economic objective as well as those between system optimality and reliability (Li et al. 2014).

Planning for NPS pollution control systems is complicated by a variety of uncertainties and nonlinearities, where difficulties exist in formulating and solving the resulting inexact nonlinear optimization problems. The application of practices to control NPS pollution is influenced by the numerous uncertain factors of the environmental and socioeconomic aspects. With the purpose of tackling such difficulties, this paper presents the development of an interval-fuzzy programming model for the combination of the farmer practices under uncertainty. The proposed approach to discuss the tradeoff between water pollution prevention, agriculture profit, and farmer practice land-use adjustment is an improvement compared to the traditional approaches to apply farmer practices in China. The way is widely suitable for agricultural watershed all over the country, although it is based on the features of a small local catchment.

The data of agricultural NPS pollution in a watershed are vital for the designing of the management practices using both simulation models and system optimization models. The precision of modeling depends on the quality of input data. Therefore, uncertainties in the control systems of nonpoint source pollution should be considered during modeling and solving. The feasibility of the designed models could be improved if enough uncertain information can be further integrated to reflect the actual agricultural system in the models.

\section{Conclusion and recommendations}

The farming practices or land-use patterns in the Wuchuan catchment need to be further improved with the consideration of both the drop of NPS water pollution and the increase of farmer income. Instead of conventional tillage systems, conservation tillage practices, such as the return of crop residues to land, is preferentially selected as the best management practice to maximize environmental benefit and to balance between the control of agricultural NPS pollution and economic cost. The second best management practice is to build multi- fishpond system in suitable areas. Crop planting should be regulated in a reasonable manner, and the amount of fertilizers applied into the fields should be reduced.

The uncertainties in the control systems of NPS pollution should be considered during modeling and problem solving procedures. The optimization process of IFLP model shows the powerful capability of combining farmer practices if the model is formulated appropriately. The capacity in undertaking scenarios analysis and in defining and managing future practices or land use leads to confidently evaluate the changes of both pollution prevention and income increase in watershed. It is not expected to be able to predict the very accurate loads of pollutants, cost of practice combination, or proportion of land-use adjustment, but it can provide a methodology to discuss the trade-off among multi-criteria.

The issues tackled in this article are experienced over a small catchment largely characterized by intensive agriculture during the watershed reformation in China. The approach presented here is suited to face a variety of scattered pollution problems over wide larger watershed and has, consequently, significant importance from the viewpoint of agricultural land-use planning. The present study integrates different techniques to design management practices by land-use adjustment to control NPS pollution and to assess the effectiveness of trade-off between water pollution prevention, agriculture profit, and farmer practice. It is suggested that these methodologies can provide a simple, but effective, management tool for decision-makers.

Acknowledgments Most of the work in this paper was funded by the Ministry of Science and Technology of China (2011BAG07B05-3), the Key Scientific Project of the Ten-Year Plan of Fujian Province of China (No. 2002H009), and the National Natural Science Foundation of China (No. 70325002). Special thanks go to Prof. Zhao Jing-zhu for his comments on the further revision of this paper.

\section{References}

Arnold, J. G., Allen, P. M., \& Bernhardt, G. A. (1993). Comprehensive surface-groundwater flow model. Journal of Hydrology, 142, 47-69.

Bartfeld, E. (1993). Point-nonpoint source trading: looking beyond the potential cost savings. Environmental Law, 23(1), 43-106.

Bhuyan, S. J., Koelliker, J. K., Marzen, L. J., \& Harrington, J. A., Jr. (2003). An integrated approach for water quality 
assessment of a Kansas watershed. Environmental Modelling \& Software, 18(5), 473-484.

Cao, W. Z., \& Zhu, H. J. (2000). Characteristics and control of regional agricultural ecosystems in Fujian province. Beijing: China Agriculture Press.

Carpenter, S. R., Caraco, N. F., Correl, D. L., Howarth, R. W., Sharpley, A. N., \& Smith, V. H. (1998). Nonpoint pollution of surface waters with phosphorus and nitrogen. Ecological Applications, 8, 559-568.

Chanas, S., \& Zielinski, P. (2000). On the equivalence of two optimization methods for fuzzy linear programming problems. European Journal of Operational Research, 121(1), 56-63.

Chang, N. B., \& Lu, H. Y. (1997). A new approach for long-term planning of solid waste management system using fuzzy global criterion. Journal of Environmental Science and Health-A, 32(4), 1025-1047.

Chen, N. W., Hong, H. S., Cao, W. Z., Zhang, Y. Z., Zeng, Y., \& Wang, W. P. (2006). Assessment of management practices in a small agricultural watershed in southeast China. Journal of Environmental Science and Health-A, 41(7), 1257-1269.

Correll, D. L. (1996). Buffer zones and water quality protection: general principles. In N. E. Haycock, T. P. Burt, K. W. T. Goulding, \& G. Pinay (Eds.), Buffer zones: their processes and potential in water protection (pp. 7-20). Hertfordshire: Quest Environmental.

Cui, L., Chen, L. R., Li, Y. P., Huang, G. H., Li, W., \& Xie, Y. L. (2011). An interval-based regret-analysis method for identifying long-term municipal solid waste management policy under uncertainty. Journal of Environmental Management, 92(6), 1484-1494.

Hassen, M., Fekadu, Y., \& Gate, Z. (2004). Validation of agricultural non-point source (AGNPS) pollution model in Kori watershed, South Wollo, Ethiopia. International Journal of Applied Earth Observation and Geoinformation, 6(2), 97-109.

Hu, Q., Huang, G. H., Cai, Y. P., \& Sun, W. (2014). Planning of electric power generation systems under multiple uncertainties and constraint-violation levels. Journal of Environmental Informatics, 23(1), 55-64.

Huang, G. H., Baetz, B. W., \& Patry, G. G. (1993). A grey fuzzy linear programming approach for municipal solid waste management planning under uncertainty. Civil Engineering Systems, 10, 123-146.

Huang, G. H., Baetz, B. W., \& Patry, G. G. (1994a). Grey dynamic programming for solid waste management planning under uncertainty. Journal of Urban Planning and Development, 120(3), 132-156.

Huang, G. H., Baetz, B. W., \& Patry, G. G. (1994b). Grey chanceconstrained programming: application to regional solid waste management planning. In K. W. Hipel \& L. Fang (Eds.), Effective environmental management for sustainable development (pp. 267-280). Dordrecht: Kluwer Academic Publishers.

Huang, G. H., Baetz, B. W., \& Patry, G. G. (1995a). Grey quadratic programming and its application to municipal solid waste management planning under uncertainty. Engineering Optimization, 23, 201-223.

Huang, G. H., Baetz, B. W., \& Patry, G. G. (1995b). Grey integer programming: an application to waste management planning under uncertainty. European Journal of Operational Research, 83, 594-620.
James, W. L., Morton, A. B., Joseph, F. D., \& Ranjithan, S. R. (2013). A generalized multistage optimization modeling framework for life cycle assessment-based integrated solid waste management. Environmental Modelling \& Software, $50,51-65$.

Jeroen, C. J. G., Walter, A. H. R., Andre, J., Derk, J. S., Henk, R., \& Martin, K. V. I. (2007). Exploring multi-scale trade-offs between nature conservation, agricultural profits and landscape quality - a methodology to support discussions on land-use perspectives. Agriculture Ecosystems and Environment, 120, 58-69.

Lee, Y. W., Bogardi, I., \& Stansbury, J. (1991). Fuzzy decision making in dredged-material management. Journal of Environmental Engineering, ASCE, 117(2), 614-628.

Li, J. B. (2003). Integration of stochastic programming and factorial design for optimal reservoir operation. Journal of Environmental Informatics, 1(2), 12-17.

Li, Y. P., Huang, G. H., Li, H. Z., \& Liu, J. (2014). A recoursebased interval fuzzy programming model for point-nonpoint source effluent trading under uncertainty. Journal of the American Water Resources Association (JAWRA), 1-17. doi:10.1111/jawr.12183.

LINDO Systems Inc. (2006). LINGO. http://indo.com/products/ lingo/lingom.html.

Liu, J. C., Zhang, L. P., Zhang, Y. Z., Chen, N. W., \& Hong, H. S. (2005). A treatment system of livestock drainage by improving land-use in dense hoggery aera, southeast China. Conference of the International-Water-Association (IWA), Future of Urban Wastewater Systems - Decentralisation and Reuse, 219-224.

Liu, J. C., Zhang, L. P., Zhang, Y. Z., \& Hong, H. S. (2005). An inexact system programming for agricultural land utilization based on non-point source pollution control in Wuchuang watershed. Conference of the International Society for Environmental Information Sciences on Environmental Informatics, Environmental Informatics, 391-397.

Liu, J. C., Zhang, L. P., Zeng, Y., Chen, N. W., Chen, W. C., Li, Y. Y., \& Hong, H. S. (2006). Mixed integer programming for a swine manure handling system in the Jiulong River Watershed. Aquatic Ecosystem Health and Management, $9(1), 33-38$.

Liu, J. C., Zhang, L. P., Zhang, Y. Z., Hong, H. S., \& Deng, H. B. (2008). Validation of agricultural non-point source pollution model (AGNPS) on a catchment in Jiulong river watershed, China. Journal of Environmental Sciences, 20(5), 599-606.

Luo, B., Maqsood, I., Yin, Y. Y., Huang, G. H., \& Cohen, S. J. (2003). Adaption to climate change through water trading under uncertainty - an inexact two-stage nonlinear programming approach. Journal of Environmental Informatics, 2(2), 58-68.

Malik, A. S., Letson, D., \& Crutchfield, S. R. (1993). Point/ nonpoint source trading of pollution abatement: choosing the right trading ratio. American Journal of Agricultural Economics, 75, 959-967.

Maqsood, I., \& Huang, G. H. (2003). A two-stage interval-stochastic programming model for waste management under uncertainty. Journal of the Air and Waste Management Association, 53, 540-552.

Nixon, S. W., Granger, S. L., \& Nowicki, B. L. (1995). An assessment of the annual mass balance of carbon, nitrogen and phosphorus in Narragansett Bay. Biogeochemistry, 35, 15-61. 
Pionke, H. B., Gburek, W. J., \& Sharpley, A. N. (2000). Critical source area controls on water quality in an agricultural watershed located in the Chesapeake Basin. Ecological Engineering, 14, 325-335.

Stewart, B. A., Woolhiser, D. A., Wischmeier, W. D., Caro, J. H., \& Frere, M. H. (1975). Control of water pollution from cropland, Volume 1, A manual for guideline development, Report Nos. EPA-600/2-75 026a and ARS H-5-1. USEPA/ USDA, Washington, D C.

Su, J., Xi, B. D., Yao, B., Huang, G. H., Lu, H. W., He, L., \& Ji, D. F. (2011). Inexact fuzzy full-infinite mixed-integer programming method for an integrated air and waste management system. Journal of Urban Planning and Development, 137(4), 370380 .

Sugiharto, T., McIntosh, T. H., Uhrig, R. C., \& Lardinois, J. J. (1994). Modeling alternatives to reduce dairy farm and watershed NPS pollution. Journal of Environmental Quality, 23, $18-24$.

US-NRC (United States National Research Council). (1993). Soil and water quality, an agenda for agriculture. Committee on Long-Range Soil and Water Conservation. Washington, DC: National Academy Press.

Vitousek, P. M., Aber, J. D., Howarth, R. W., Likens, G. E., Matson, P. A., Schindler, D. W., Schlesinger, W. H., \& Tilman, D. G. (1997). Human alteration of the global nitrogen cycle: sources and consequences. Ecological Applications, 7, 737-750.

Wang, S., \& Huang, G. H. (2013a). A two-stage mixed-integer fuzzy programming with interval-valued membership functions approach for flood-diversion planning. Journal of Environmental Management, 117, 208-218.

Wang, S., \& Huang, G. H. (2013b). An interval-parameter twostage stochastic fuzzy program with type-2 membership functions: an application to water resources management. Stochastic Environmental Research and Risk Assessment, 27, 1493-1506.

Wang, S., Huang, G. H., Lu, H. W., \& Li, Y. P. (2011). An intervalvalued fuzzy linear programming with infinite $\alpha$-cuts method for environmental management under uncertainty. Stochastic Environmental Research and Risk Assessment, 25(2), 211222.

Wang, X. W., Cai, Y., Chen, J. J., \& Dai, C. (2013). A greyforecasting interval-parameter mixed-integer programming approach for integrated electric-environmental management - a case study of Beijing. Energy, 63, 334-344.

Yeomans, J. S., \& Huang, G. H. (2003). An evolutionary grey, hop, skip, and jump approach: generating alternative policies for the expansion of waste management. Journal of Environmental Informatics, 1(1), 37-51.

Yeomans, J. S., Huang, G. H., \& Yoogalingam, R. (2003). Combining simulation with evolutionary algorithms for optimal planning under uncertainty: an application to municipal solid waste management planning in the regional municipality of Hamilton-Wentworth. Journal of Environmental Informatics, 2(1), 11-30.

Zhang, Y. Z. (2003). Study on agricultural non-point source pollution of Wuchuan catchment in upstream Jiulong River. Xiamen: Xiamen University.

Zhang, M., Liu, Q. Y., Chen, D. Y., Li, J. Y., \& Ao, Y. H. (2009). Environmental pressure of contamination from livestock and poultry and its risk assessment in Shenyang. Journal of Shenyang Agricultural University, 40(6), 698-702.

Zou, R., Lung, W. S., Guo, H. C., \& Huang, G. H. (2000). Independent variable controlled grey fuzzy linear programming approach for waste flow allocation planning. Engineering Optimization, 33(1), 87-111. 